\title{
Committee Report: Advancing the current recommended panel of conditions for newborn screening
}

Nancy S. Green, $M D^{1}$, Piero Rinaldo, $M D, P h D^{2}$, Amy Brower, $P h D^{3}$, Coleen Boyle, PhD, MS ${ }^{4}$, Denise Dougherty, PhD ${ }^{5}$, Michele Lloyd-Puryear, $M D, P h D^{6}$, Marie Y. Mann, $M D, M P H^{6}$, Rodney R. Howell, $\mathrm{MD}^{7}$, for the Advisory Committee on Heritable Disorders and Genetic Diseases in Newborns and Children

\begin{abstract}
The Advisory Committee on Heritable Disorders and Genetic Diseases in Newborns and Children is charged with advising the Secretary of the US Department of Health and Human Services in areas relevant to heritable conditions in children, especially newborn screening (NBS). This report describes the formulation by the Committee of a new process to nominate and review conditions to the recommended universal NBS panel. Nominations are currently being solicited. Committee review will adhere to the fundamental principles of being transparent, broadly accessible, evidence-based and consistent across the process for all of the proposed conditions across the
\end{abstract} process. Genet Med 2007:9(11):792-796.

Key Words: newborn screening, genetic screening, evidence-based review, heritable disorders, nomination process

Rapid advancements in several key aspects of newborn screening (NBS) have combined to enhance awareness and investment in NBS: an increasing understanding of the contribution of genetics to diseases of childhood, the development of novel therapies, the creation of technologies applicable to dried bloodspots and other mechanisms for efficient screening, and heightened public enthusiasm for the health-preserving benefits of NBS in children with identifiable and treatable conditions.

In the United States, NBS programs are the responsibility of the individual states, which determine those conditions to include in its own NBS panel. This individual approach by the states has been responsible for the significant variability in the

From the ${ }^{1}$ Department of Pediatrics, Columbia University Medical Center, New York, New York; the ${ }^{2}$ Mayo Clinic, Rochester, Minnesota; ${ }^{3}$ Third Wave Molecular Diagnostics, South Sioux City, Nabraska; the ${ }^{4}$ Centers for Disease Control and Prevention, US Department of Health and Human Services, Atlanta, Georgia; the ${ }^{5}$ Agency for Healthcare Research and Quality, US Department of Health and Human Services, Rockville, Maryland; the ${ }^{6}$ Health Resources and Services Administration, US Department of Health and Human Services, Rockville, Maryland; and the ${ }^{7}$ Department of Pediatrics, University of Miami, Coral Gables, Florida.

Michele A. Lloyd-Puryear, MD, PhD, Maternal and Child Health Bureau, HRSA, 5600 Fishers Lane.Rm 18-A-19, Rockville, MD 20857.E-mail: mpuryear@hrsa.gov.

Disclosure: The authors declare no conflict of interest.

The findings and conclusions in this report are those of the authors and do not necessarily represent the views of the Agency for Healthcare Research and Quality, the Centers for Disease Control and Prevention, the Health Resources and Services Administration, or the U.S. Department of Health and Human Services.

Supplementary figures are available via the Article Plus feature at www.geneticsinmedicine. org. Please go to the November issue and click on the Article Plus link posted with the article in the Table of Contents to view this material.

Submitted for publication July 24, 2007.

Accepted for publication August 10, 2007.

DOI: $10.1097 /$ GIM.0b013e318159a38e numbers and types of conditions that are included in the NBS panels. ${ }^{1}$ No federal entity has the authority to mandate that states will screen for, and manage, certain conditions.

The Advisory Committee on Heritable Disorders and Genetic Diseases in Newborns and Children (Committee, Appendix A) was chartered in February 2003 to advise the Secretary of the federal Department of Health and Human Services in many areas surrounding heritable conditions in children, and specifically in the area of NBS. ${ }^{2}$ The Committee is directed to review and report regularly on newborn and childhood screening practices for heritable disorders, to recommend improvements in the national newborn and childhood heritable screening programs, and to engage in the following activities:

1. Provide advice and recommendations to the Secretary concerning grants and projects awarded or funded under the designated authorizing Public Health Service (PHS) Act;

2. Provide technical information to the Secretary for the development of policies and priorities for the administration of grants under the designated PHS act; and

3. Provide such recommendations, advice or information as may be necessary to enhance, expand or improve the ability of the Secretary to reduce the mortality or morbidity in newborns and children from heritable disorders.

Early discussions of the Committee focused on the recommendations from a NBS expert panel convened by the American College of Medical Genetics (ACMG) at the request of the Health Resources and Services Administration (HRSA). The recommendations from the ACMG expert panel received considerable support from the public, medical, and affiliated pro- 
fessional organizations, though some dissenting opinions were expressed (Ref. 3, for example). The Committee also endorsed this report and its recommendations in September 2005. ${ }^{2}$ Subsequently, the ACMG report was published, ${ }^{4}$ and a majority of states expanded their screening panels to include many, if not all, of the recommended conditions. ${ }^{5}$

Although the number of screened conditions expanded, many other conditions were not included because of lack of information about the condition and its natural history, proven therapies, and/or a technology to detect the condition on a population-wide scale. To facilitate the inclusion of emerging evidence and novel technologies, the Committee, with input from key stakeholders, outlined a process for nomination and evidence review. In prospectively determining the process that will be used for the "nomination" of conditions to be considered for NBS, a critical area of discussion focused on how evidence supporting such a nomination is gathered, and importantly how the evidence is evaluated. It has been the consensus of the Committee that an independent scientific body will be established to evaluate the evidence related to adding conditions to the uniform panel. This body will then refer its objective assessment to the full Committee for review, recommendations, and management.

A key issue in the evaluation of evidence for NBS is that virtually all the conditions considered for screening pose serious health risks to those affected and are present at very low frequencies in the general pediatric population in the United States. Therefore, even when data suggest that health benefits for these rare conditions result from early recognition and treatment, the evidence is most likely not derived from a randomized control trial (RCT) even though a RCT is the most accepted type of evaluation used to judge treatment effectiveness. Furthermore, some of the evidence for treatment efficacy resides not in the peer-reviewed published literature but is proprietary and/or in the domain of the Food and Drug Administration. Therefore, new ground rules for weighing evidence will be needed to assess the validity of claims for health benefits to justify NBS for each disorder.

This report describes the formulation of that new process to nominate and review conditions for the recommended universal panel. The Committee agreed on the following fundamental principles for the nomination and review process of conditions: (1) The deliberative process will be rigorously evidence-based, even for relatively rare conditions; (2) The procedures for the creation of a deliberative system and the system itself will be transparent and accessible to the scientific and lay public; (3) The process will be consistent across the different phases of the review process and applied to all of the proposed conditions (http://mchb.hrsa.gov/ programs/genetics/committee/).

\section{THE NOMINATION PROCESS}

The Committee chair, Dr. R. Rodney Howell, appointed a Criteria Work Group to develop a system for consideration of new conditions and regularly report to the Committee. This

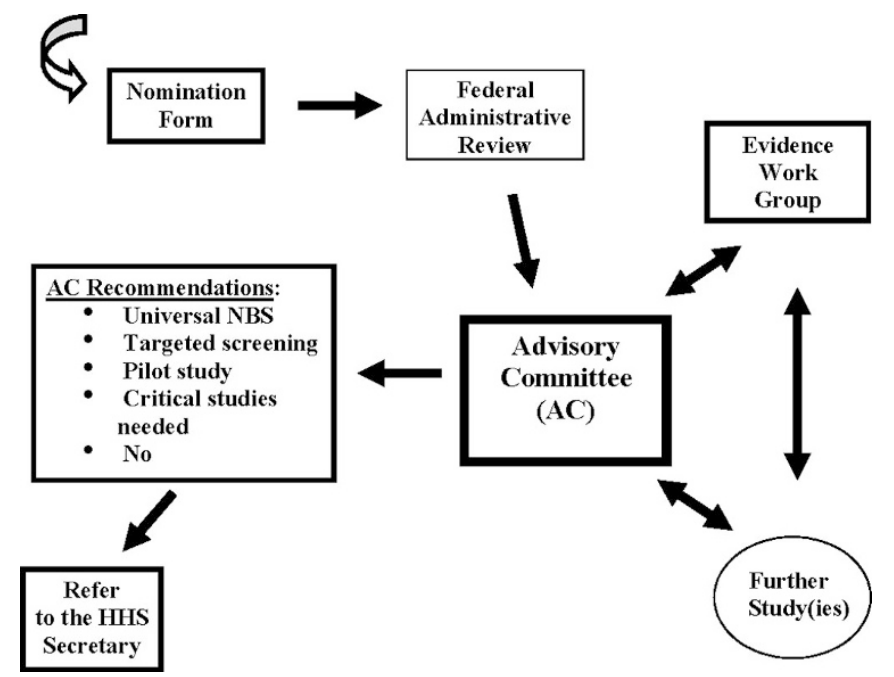

Fig. 1. Process for considering the addition of disorders to the existing NBS uniform minimum panel.

work group was comprised of members of the Committee (voting and nonvoting members, see Appendix A), and had HRSA administrative support.

The Criteria Work Group proposed a Nomination Form (available online only; also available at: ftp://ftp.hrsa.gov/mchb/ genetics/NominationForm.pdf) and an overall process for the nomination and evidence review process by the Committee. Submission of the Nomination Form would initiate the consideration of any new condition as the first of a three-step approach (Fig. 1). The second step would be an administrative review of the Nomination Form led by HRSA to ensure that the Form conformed to expectations for completeness. Then the Committee would review the Nomination Form to determine whether the nomination should go to formal scientific review or deferral of review until additional information could be provided by the nominator.

The proposed Nomination Form conformed to the general structure of the survey instrument used by ACMG to solicit expert input for the NBS report, ${ }^{4}$ requiring information on three main aspects: the condition, the screening and diagnostic tests, and the treatment(s). In the presumed dearth of formal randomized controlled studies of screening, pilot screening data would be an essential element of the evidence to be considered in the nomination process. The Nomination Form also required citation of key supporting references, preferably from the scientific literature, but including expert opinion. Moreover, the points of focus for the Nomination Form needed to be consistent with all subsequent deliberative review for any condition. The Form was subsequently piloted for use by a number of medical experts and advocacy groups with a variety of conditions. Based on the results of that pilot, and public input, the Committee revised the Nomination Form and subsequently approved of its use. A single caveat was that until the entire review process was described and codified, the final Form could still undergo modification to assure consistency of evaluation throughout the review process. 


\section{FORMAL SCIENTIFIC REVIEW}

The third and most complex phase of the new process, formal scientific review, was envisioned by the Criteria Work Group as a multiphased process outlined in the algorithm (Fig. 1). The fulcrum of scientific deliberation is an evidence-based review (EBR), developed by an Evidence Review Work Group (Evidence Workgroup) and described below. Engagement of the Evidence Workgroup will be triggered by the Committee for those nominated conditions considered to be ready for consideration (see algorithm) and will function semi-independently from the Committee, with two Committee members serving as liaison to the EBR on a rotating basis. EBR will occur through a structured process that conforms to national standards for EBR, ${ }^{6}$ while accommodating the paucity of data on clinical outcomes for rare genetic disorders. The evidence review will include the strength of data supporting screening, diagnosis, and treatment for a particular condition. The Evidence Workgroup will present its analysis and findings to the Committee. The report to the Committee will consist of a presentation of findings, rather than specific recommendations for inclusion or exclusion in NBS.

Subsequently, the Committee deliberations and recommendations will be published and presented to the HHS Secretary, taking into consideration the findings of the Evidence Workgroup, as well as consideration about cost and value of screening. Recommendations could range from addition of new conditions, rejection, and identification of areas where more research is needed, such as the performance characteristics of the screening test (sensitivity and specificity) and the efficacy of treatment on averting the adverse outcomes of the disorder. This process was accepted by the Committee. ${ }^{2}$

\section{THE NOMINATION FORM}

The Nomination Form requires a description of the qualifications and background of the person(s) submitting the nomination, and a number of key characteristics defining the condition, testing, and treatment (available online only), accompanied by supporting references. The technical expertise required by the Nomination Form to produce an informative and acceptable nomination may demand coordinated input from experts in medical genetics, pediatric, and other specialty practitioners, researchers in specific conditions and tests, and parents caring for affected children, as well as disease-specific parent groups and/or from an umbrella group such as the Genetic Alliance. ${ }^{7}$

Specific descriptions are required within the category of the condition: a succinct definition of the exact condition under consideration; the estimated incidence within the general newborn population; the type, timing, and degree of health threats to the newborn and/or child; its clinical spectrum of signs and symptoms. These data preferably will be derived from population-based pilot screening endeavors, although the Committee recognizes that this is not possible in all cases.
The section of the Nomination Form pertaining to the screening and diagnostic tests requires data on: sensitivity; specificity; clinical utility (estimated rates of false negatives and false positives); whether the screening test can be done on a Guthrie dried bloodspot card or requires additional approaches and/or technologies; if the appropriate timing of testing comports with that normally obtained through current screening procedures (i.e., first 1-2 weeks of life); if screening identifies or suggests the presence of conditions other than the targeted condition; definitive diagnostic testing also requires data about its reliability and availability.

The section on Treatment requires the provision of data on a description of current therapy(ies) and the extent to which they ameliorate the medical impact of the condition; the urgency of treatment on averting disease sequelae; potential risks of and barriers to treatment; and the availability of treatment for affected children.

A limited number of key references will be required for statements and data cited on the Nomination Form. Lastly, clear and complete statement from the nominator(s) of potential conflicts-of-interest declarations will be required.

\section{EVIDENCE-BASED REVIEW}

Under contract from HRSA, an Evidence Workgroup will be established for three purposes:

1. Initially propose definitions for the terms used in the Nomination Form;

2. Delineate an evidence revaluation process based on the principles of evidence-based review. The analytic framework will include specifying the processes for gathering and weighing the evidence, defining the criteria for inclusion and exclusion, and evaluating the quality of studies and the strength of the body of evidence. A protocol will be developed for systematic scientific literature search and analysis, as well as a model of the summary evidence tables to be used to present the Evidence Workgroup's data and findings for each review;

3. Conduct systematic reviews and syntheses of evidence for conditions as requested by the Committee.

The Evidence Workgroup will possess core expertise in general pediatrics, genetics, public health, epidemiology and evidence-based review methodology, and a consumer (parent of a child with a heritable disorder). Two members of the Committee also will serve on a rotating basis as nonvoting liaisons to the Evidence Workgroup.

In addition, the Evidence Workgroup will provide guidance to the Committee on determining a framework for assessing the relative costs involved in NBS and treatment for children diagnosed and treated early in life versus those detected by natural history and presenting complications. Other areas of interest for which the Evidence Workgroup will provide guidance are in managing conflict of interest within the Committee and the evidence review process. Additional input on the work of the Evidence Workgroup will be provided by an external expert review group, which 
will be recommended by the leader of the Evidence Workgroup and approved by the Chair of the Committee.

\section{NEXT STEPS}

The nomination process began in June 2007, as the Nomination Form and cover letter are available on the HRSA Website (http://mchb.hrsa.gov/programs/genetics/committee/ default.htm) for electronic or paper submission. Administrative review is underway, and completed forms will be forwarded to the Committee. Once the Evidence Workgroup and its structure for EBR has been reviewed and endorsed by the Committee, the committee will begin its deliberations and begin forwarding nominated conditions for EBR or returning them for further information. After the EBR is presented to the Committee, it will formulate a recommendation to the HHS Secretary. Those recommendations will be to add the condition to the uniform NBS panel or not, as well as to formulate any additional research questions that would address the appropriateness of screening and/or treatment for that condition. If a condition is not ready for national implementation, the Committee can recommend that pilot studies be conducted to gather further information about the condition, the tests, or treatment. In the early phases of this process, the Committee will solicit public input to continue to inform its work around recommendations via the regular Committee meetings and related processes. The first full review should be completed by mid-2008. Health professionals and consumers are now encouraged to submit collaboratively prepared nominations.

Following addition of any new condition(s) into the uniform panel, an evaluative process will be put in place to assess the impact of these additions on the quality and cost of expanded screening on state NBS programs. The screening community, parents, and pediatric providers will need to provide the essential data for that evaluation, the scope and method of which will need to be determined at or before implementation of expanded screening.

The impact of NBS on the health of the nation's newborns and children is vast, affecting the more than four million infants born annually in the United States, and potentially influencing screening programs abroad. Our ability to expand screening based on our rapidly advancing knowledge and increasing advancements in technology create the need for a careful and transparent process that builds consensus from the varied professional and lay communities engaged in NBS and policy development.

\section{APPENDIX A}

\section{Members of the advisory committee on heritable disorders and genetic disease in newborns and children}

Amy Brower, PhD, Executive Director, Medical Informatics and Genetics, Third Wave Molecular Diagnostics, 315 South Fork Place, South Sioux City, NE 68776, Phone: (608) 358-1574.

Peter B. Coggins, PhD, President, PerkinElmer Life and Analytical Sciences, Senior Vice President, PerkinElmer, 549 Al- bany Street, Boston, MA 02118, Phone: (617) 350-9169, Fax: (617) 350-9454.

Gregory A. Hawkins, PhD, Associate Professor, Department of Internal Medicine, Section on Pulmonary, Critical Care, Allergy and Immunologic Diseases, Center for Human Genomics, Wake Forest University School of Medicine, Medical Center Boulevard, Winston-Salem, NC 27157-1054, Phone: (336) 713-7511, Fax: (336) 713-7566.

R. Rodney Howell, MD, Committee Chairperson, Professor, Department of Pediatrics (D820), Leonard M. Miller School of Medicine, University of Miami, PO Box 016820, Miami, FL 33101, Phone: (305) 243-1073, Fax: (305) 243-1075.

Jana Monaco, 3175 Ironhorse Drive, Woodbridge, VA 22192, Phone: (703) 497-1216.

James A. Newton, MD, President, Alabama Neonatal Medicine, P.C., 7203 Copperfield Drive, Montgomery, AL 36117, Phone: (334) 215-8411.

Piero Rinaldo, MD, PhD, Professor of Laboratory Medicine, T. Denny Sanford Professor of Pediatrics, Vice-Chair of Academic Affairs and Intramural Practice, Department of Laboratory Medicine and Pathology, Mayo Clinic College of Medicine, 200 First Street, Southwest, Rochester, MN 55905, Phone: (507) 284-5859, Fax: (507) 266-4176.

Michael Skeels, PhD, MPH, Director, Oregon State Public Health Laboratory, 1717 SW Tenth Avenue, Portland, OR 97201, Phone: (503) 229-5882.

\section{Liaison members}

James W. Collins, Jr., MD, MPH, Chairman, Secretary's Advisory Committee on Infant Mortality, Associate Professor of Pediatrics Department of Pediatrics, Division of Neonatology, Children's Memorial Hospital, Chicago, IL 60614, Phone: (773) 880-4142, Fax: (773) 880-3061.

Joseph Telfair, DrPH, MSW, MPH, Professor, Public Health Research and Practice, Department of Public Health Education, School of Health and Human Performance, University of North Carolina at Greensboro, 437 HHP Building, 1408 Walker Avenue, PO Box 26170, Greensboro, NC 27402-6170, Phone: (336) 334-4777, Fax: (336) 334-3238.

\section{Ex-officio members}

Duane Alexander, MD, National Institutes of Health, Director, National Institute of Child Health and Human Development, 31 Center Drive, Room 2A03, Mail Stop Code 2425, Bethesda, MD 20892-2425, Phone: (301) 496-3454, Fax: (301) 402-1104.

Coleen Boyle, PhD, MS, Centers for Disease Control and Prevention, Director, Division of Birth Defects and Developmental Disabilities, Division of National Center on Birth Defects and Developmental Disabilities, 1600 Clifton Road, Mailstop E86, Atlanta, GA 30333, Phone: (404) 498-3907, Fax: (404) 498-3550.

Denise Dougherty, PhD, Agency for Health care Research and Quality, Senior Advisor, Child Health, 540 Gaither Road, Rockville, MD 20850, Phone: (301) 427-1868, Fax: (301) 427-1561.

Peter C. van Dyck, MD, MPH, MS, Health Resources and Services Administration, Associate Administrator, Maternal and Child Health Bureau, Parklawn Building, 5600 Fishers 
Lane, Room 18-05, Rockville, MD 20857, Phone: (301) 4432170, Fax: (301) 443-1797.

\section{Executive secretary}

Michele A. Lloyd-Puryear, MD, PhD, Health Resources and Services Administration, Chief, Genetic Services Branch, Maternal and Child Health Bureau, Parklawn Building, 5600 Fishers Lane, Room 18A-19, Rockville, MD 20857, Phone: (301) 443-1080, Fax: (301) 443-8604.

\section{Organization representatives}

American Academy of Family Physicians: Norman B. Kahn, Jr., MD, Vice President, Science and Education, American Academy of Family Physicians, 11400 Tomahawk Creek Parkway, Leawood, KS 66211-6272, Phone: (913) 906-6000, ext. 6500, Fax: (913) 906-6107.

American Academy of Pediatrics: E. Stephen Edwards, MD, FAAP, American Academy of Pediatrics, Past-President,,2700 Conover Court, Raleigh, NC 27612-2919, Phone: (919) 7821174, Fax: (919) 781-5177.

American College of Obstetricians and Gynecologists: Anthony R. Gregg, MD, Director, Maternal Fetal Medicine, Medical Director of Genetics, Department of Obstetrics and Gynecology, University of South Carolina School of Medicine, Two Medical Park, Suite 208, Columbia, SC 29203, Phone: (803) 779-4928 ext. 252, Fax: (803) 434-7756.

Association of State and Territorial Health Officials: Christopher Kus, MD, MPH, Pediatric Director, Division of Family Health, New York State Department of Health, Empire State Plaza, Room 890 Corning Tower Building, Albany, NY 12237, Phone: (518) 474-6968, Fax: (518) 473-2015.

Child Neurology Society: Bennett Lavenstein, MD, Child Neurology Society, Neurology Department, Children's Na- tional Medical Center, 111 Michigan Avenue, Washington, DC 20010, Phone: (202) 884-6230, Fax: (202) 884-5226.

Department of Defense: Lt. Col. David S. Louder, III, MD, Chief Consultant for Maternal-Child Medicine, Air Force Medical Corps, AFMSA/SGOC, 110 Luke Avenue, Room 405, Bolling AFB, DC 20032, Phone: (202) 767-4073, Fax: (202) 404-7361.

Food and Drug Administration: Ethan D. Hausman, MD, FAAP, FCAP, Medical Officer, Inborn Errors of Metabolism Team, Division of Gastroenterology Products, WO-22, Room 5171, HFD-180, US FDA, CDER, OND, ODE-3, 10903 New Hampshire Avenue, Silver Spring, MD 20993-0002, Tel: 301796-2178, Fax: 301-796-9894.

March of Dimes Birth Defects Foundation (Until March 2007): Nancy S. Green, MD, Medical Director, March of Dimes Birth Defects Foundation, 1275 Mamaroneck Avenue, White Plains, New York 10605, Phone: (914) 997-4262, Fax: (914) 997-4576.

\section{References}

1. Serving the family from birth to the medical home. Newborn screening: a blueprint for the future- a call for a national agenda on state newborn screening programs. Pediatrics 2000;106(Suppl 2):389-422.

2. The Advisory Committee on Heritable Disorders and Genetic Diseases in Newborns and Children, meeting minutes. Available at: http://mchb.hrsa.gov/programs/ genetics/committee/default.htm. Accessed June 1, 2007.

3. Natowicz M. Newborn screening — setting evidence-based policy for protection. N Engl J Med 2005;353:867-870.

4. Watson MS, Mann MY, Lloyd-Puryear MA, Rinaldo P, et al. Newborn screening: toward a uniform screening panel and system (ACMG report). Genet Med 2006;8:S1S252.

5. National Newborn Screening and Genetics Resource Center. Available at: http:// genes-r-us.uthscsa.edu. Accessed June 1, 2007.

6. http://www.ahrq.gov/clinic/ajpmsuppl/harris1.htm. Accessed June 4, 2007.

7. www.geneticalliance.org. Accessed June 4, 2007. Fig. 1. The Nomination. Reprinted with permission from Ref. 2 . 